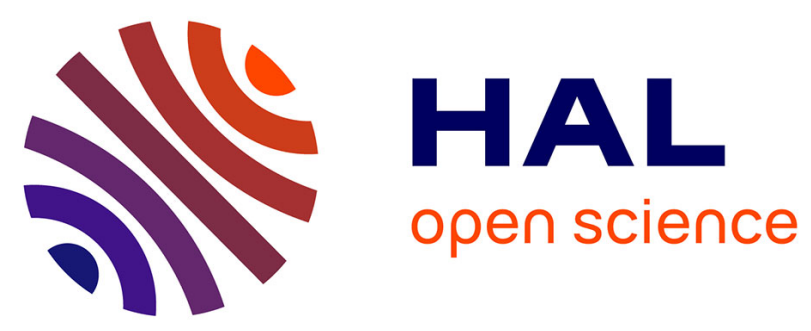

\title{
Experimental Acoustic Data Analysis for Fish Detection using an Active Ultrasound System
}

Gabriel Vasile, Alexandre Girard, Eric Guy d'Urso, Eric de Oliveira, Franck Hieramente, Olivier Philippe

\section{- To cite this version:}

Gabriel Vasile, Alexandre Girard, Eric Guy d'Urso, Eric de Oliveira, Franck Hieramente, et al.. Experimental Acoustic Data Analysis for Fish Detection using an Active Ultrasound System. OCEANS 2019 - OCEANS '19 MTS/IEEE. Blue Sea, Blue Sky, Blue Tech, Oct 2019, Seattle, United States. 10.23919/OCEANS40490.2019.8962806 . hal-02346489

\section{HAL Id: hal-02346489 \\ https://hal.science/hal-02346489}

Submitted on 5 Nov 2019

HAL is a multi-disciplinary open access archive for the deposit and dissemination of scientific research documents, whether they are published or not. The documents may come from teaching and research institutions in France or abroad, or from public or private research centers.
L'archive ouverte pluridisciplinaire HAL, est destinée au dépôt et à la diffusion de documents scientifiques de niveau recherche, publiés ou non, émanant des établissements d'enseignement et de recherche français ou étrangers, des laboratoires publics ou privés. 


\title{
Experimental Acoustic Data Analysis for Fish Detection using an Active Ultrasound System
}

\author{
Gabriel Vasile \\ Grenoble-Image-sPeech-Signal-Automatics Lab \\ CNRS / Université Grenoble Alpes \\ 11 rue des Mathématiques \\ Grenoble Cedex, France, F-38402 \\ gabriel.vasile@grenoble-inp.fr
}

\author{
Alexandre Girard, Guy d'Urso and Eric De Oliveira \\ Laboratoire National d'Hydraulique et Environnement \\ EDF R\&D LNHE \\ 6 quai Watier \\ Chatou, France, F-78400 \\ alexandre.girard@edf.fr, guy.durso@edf.fr, eric.de-oliveira@edf.fr
}

\author{
Franck Hieramente and Olivier Philippe \\ OSEAN S.A.S. \\ ZAE la Bayette \\ Le Pradet, France, F-83220 \\ franck.hieramente@osean.fr, olivier.philippe@ osean.fr
}

\begin{abstract}
This paper proposes the supervised classification of different acoustics signatures employed for fish monitoring by active ultrasound systems. The obtained results are analysed, both qualitatively and quantitatively, by taking into consideration three target types (trout, wood and vegetal debris).
\end{abstract}

\section{INTRODUCTION}

Allowing hydropower plants and river system biodiversity coexisting requires sustainable solutions involving multiple economic, social and environmental aspects. The impact of hydropower plants on the migrating fish species needs to be carefully and continuously monitored in order to minimise any eventual perturbation on the actual migration process. The European Commission has published a set of recommendations for the use of dedicated passage channels (or fish passes) to by-pass the fish migration paths and to allow the upstream migration of fish species (salmon, trout, eel ...) [1].

The monitoring of fish passages in a channel is currently addressed by employing several techniques, such as camera (visible or infrared), passive sonars, active acoustic or RFID tagging [2], [3], [4], [5]. In this work, we present our recent advances in the field of active ultrasound fish detection capabilities developed in the framework of the FEDER PACA ACOUEAU $^{1}$ European Project. The main goal is to develop multiple acoustic barriers for reliable fish counting in downstream fish passes.

Each acoustic barrier is composed of a conventional emission-reception ultrasound path that is affected by the passage of any external object [6], [7], [8], [9], [10]. The proper use of this technique relies on two main hypotheses. The first one concerns the Signal-To-Noise (SNR) ratio, namely any fish passage will decrease the received SNR by a significant amount (at least 25\%). This has been insured by employing advanced signal processing [11], [12], [13] techniques such as

\footnotetext{
${ }^{1}$ http://www.osean.fr/fr/feder-acou-eau.php
}

adaptive acoustic channel equalisation [14] coupled with the use of wideband transmission waveforms [15].

The second hypothesis relies on the ability to recognise the external perturbation on the acoustic path. The proposed algorithm relies on supervised machine learning techniques in order to be able to decide which acoustic signature corresponds to the specific target type.

This paper is structured as follows. Section II illustrates in several steps the proposed target classification algorithm for the underwater fish monitoring system, while Section III presents both qualitative and quantitative performance assessment. Section IV concludes the paper.

\section{ACOUSTIC SIGNATURE CLASSIFICATION ALGORITHM FOR FISH RECOGNITION}

The proposed signal processing algorithm is composed of two stages:

- the training step - a training database is used to extract the information required for the acoustic signature characterisation;

- the recognition step - using the previously derived target descriptors, the final decision criterion is computed.

In all cases, a preprocessing step is required in order to cancel the propagation effects of the bistatic system and its environment: several acoustic recordings are performed without any target present and the median spectrum is computed $X_{f}^{r e f}$. The following normalisation is performed for each additional recording $X_{f}^{\text {norm }}$ in the frequency domain :

$$
X_{f}^{\text {norm }}=\frac{X_{f}}{X_{f}^{r e f}+\beta},
$$

where $\beta$ is a regularisation term. The normalised signal $x^{n o r m}(t)$ is obtained by taking the inverse Fourier transform after spectral normalisation. For simplicity, $x^{n o r m}(t)$ is denoted by $x(t)$ in the following, 


\section{A. Training}

This step requires a training database $[X]^{\text {train }}$ arranged as a 3D tensor of size $N \times n \times m$, where $N$ is the number of samples and $n$ is the number of signals available for each of the $m$ targets. It can be summarised as:

1) compute the Hilbert transform of each signal $[X]_{\text {Hilbert }}^{\text {train }}$ along the dimension $N$;

2) evaluate the Fast Fourier Transform (FFT) $[X]_{F F T}^{\text {train }}$ along the same dimension;

3) take the mean over the dimension $n$ to derive $[X]_{\text {mean }}^{\text {train }}$;

4) perform the inverse FFT (iFFT) along $N$ to derive $[X]_{\text {reference. }}^{\text {train }}$.

The derived matrix $[X]_{\text {reference }}^{\text {train }}$ of size $N \times m$ is completely characterising each of the $m$ targets of interest.

\section{B. Recognition}

Using the previously derived reference functions, each recorded signal under test $x^{\text {test }}$, of size $N$, is processed according to the following steps:

1) compute the Hilbert transform $x_{\text {Hilbert }}^{\text {test }}$;

2) for each $i \in\{1 . . m\}$ target types, compute the corresponding match filter $x_{M F_{i}}^{\text {test }}$;

3 ) the received signal is assign to the dominant target type $k$ according to the criterion

$$
k=\operatorname{argmax}_{i \in\{1 . . m\}}\left\{M A X_{N}\left|x_{M F_{i}}^{\text {test }}\right|\right\} .
$$

The final classification label is set according to the criterion from Eq. 2, which is maximised when the acoustic signature is identical to the class reference function.

\section{RESULTS AND DISCUSSION}
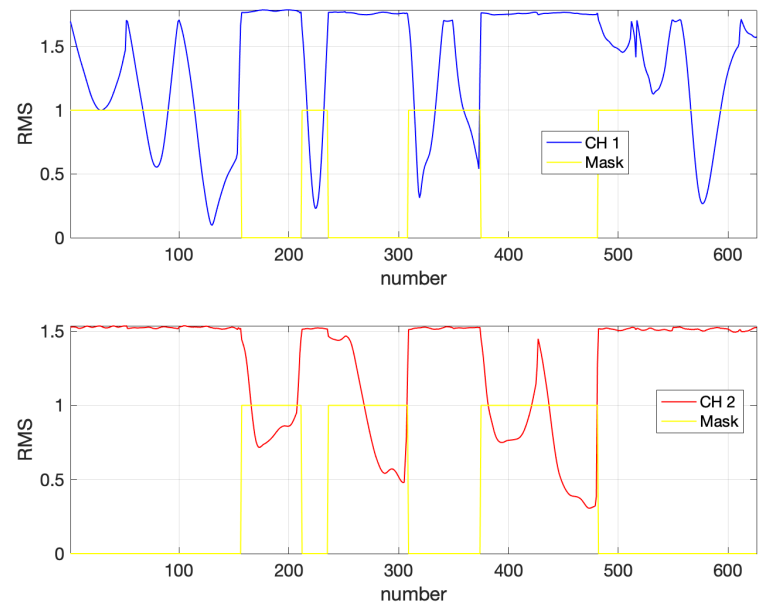

Fig. 1. Active ultrasound fish detection, $500 \mathrm{KHz}$ central frequency: selection of training and testing datasets for the trout target type.

In order to validate the proposed algorithm, an experimental campaign has been realised in controlled environment (EDF Chatou Lab) in February 2018. During this experimentation,
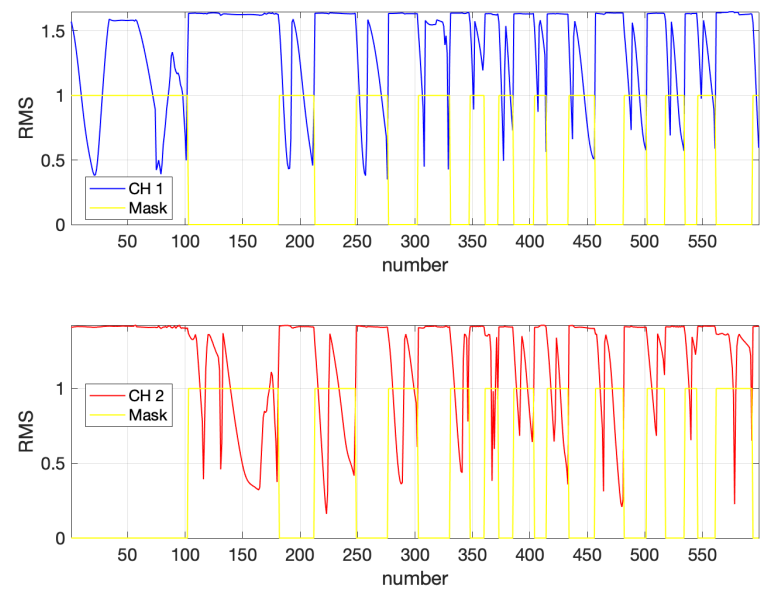

Fig. 2. Active ultrasound fish detection, $500 \mathrm{KHz}$ central frequency: selection of training and testing datasets for the wood target type.
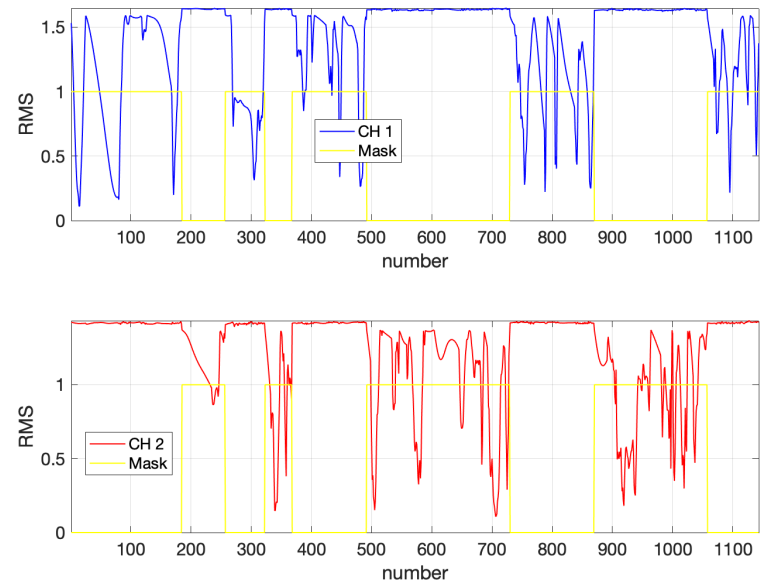

Fig. 3. Active ultrasound fish detection, $500 \mathrm{KHz}$ central frequency: selection of training and testing datasets for the leaves target type.

the ultrasound transducers operated at $500 \mathrm{KHz}$ central frequency, with $m=3$ representative target types: trout, wood and vegetal debris (leaves).

Figs. 1, 2, 3 illustrate the RMS function of the acquisition number and the corresponding detected passages for the trout target type. In order to ensure equal representation, the final training and testing datasets were constructed by randomly selecting $n=117$ representative passages of each target. Notice two individual acoustic barriers were used $(\mathrm{CH} 1$ and $\mathrm{CH} 2$ ) in this study.

Figs. 4 and 5 illustrate the median, the $5 \%$ and the $95 \%$ quantiles for both the spectrum, after band-pass filtering, and the conventional match filtering results (using the corresponding background reference function, only).

One can notice that direct thresholding on the signals from Figs. 4 and 5 cannot provide a reliable technique to recognise 

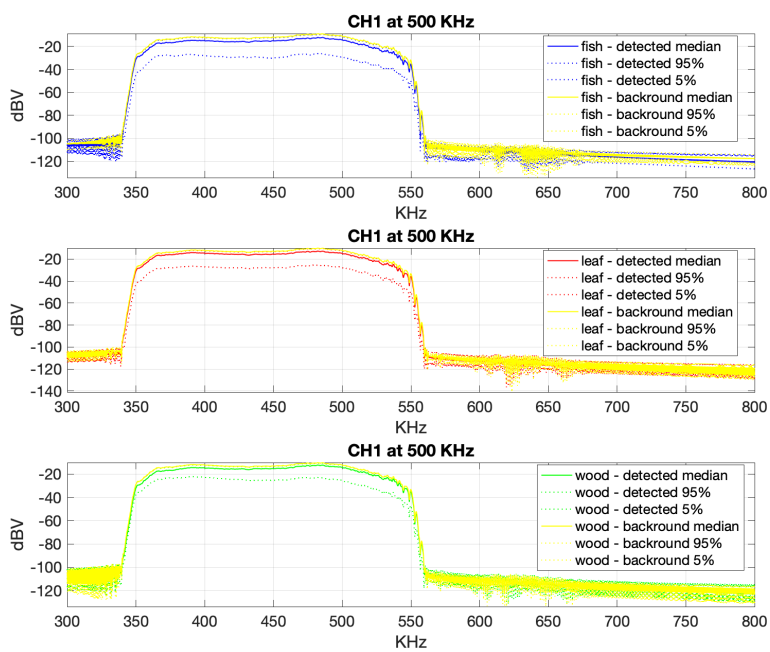

(a)
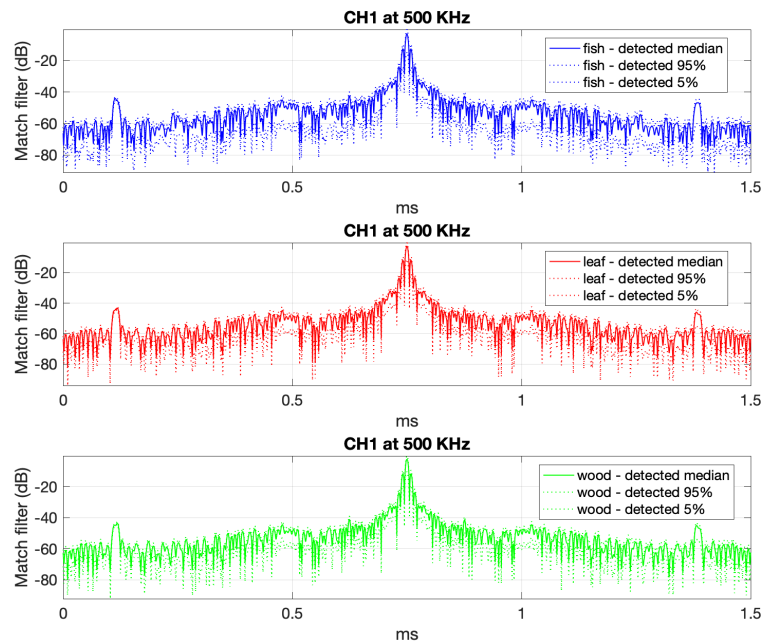

(b)

Fig. 4. Active ultrasound fish detection, $500 \mathrm{KHz}$ central frequency, $\mathrm{CH} 1$ : (a) spectrum and (b) conventional match filtering using the background reference function, only.

each of the three target types.

The final classification result is presented in Fig. 6-(a),(b). The proposed method is showing excellent performances in terms of trout recognition, especially on $\mathrm{CH} 2$ (the lower acoustic barrier). This can be explained by the fact that this barrier was subject to less additional multi-path perturbations.

Finally, quantitative performance assessment is shown in Fig. 7 by computing the corresponding confusion matrices for $\mathrm{CH} 1$ and $\mathrm{CH} 2$.

\section{CONCLUSION}

This paper proposed a method to classify acoustic signatures provided by different acoustic barriers in order to be able to perform fish counting in a time varying shallow water
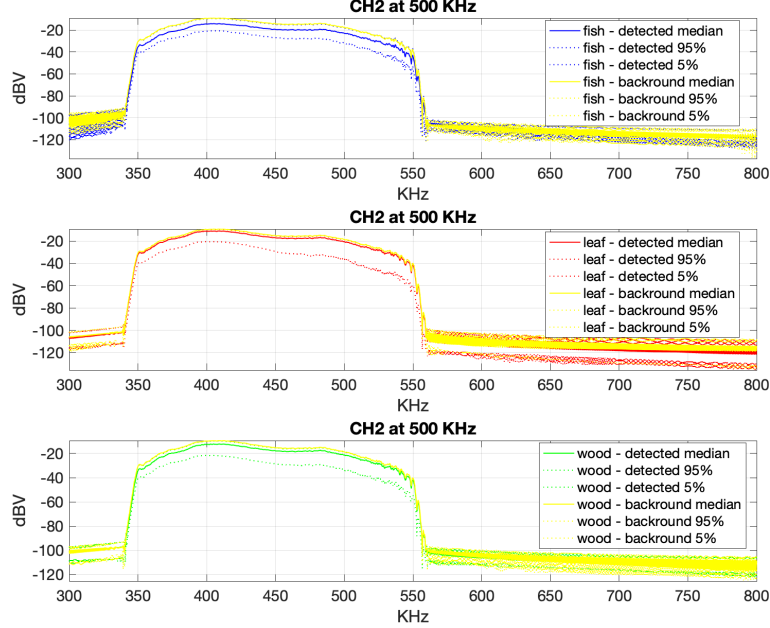

(a)
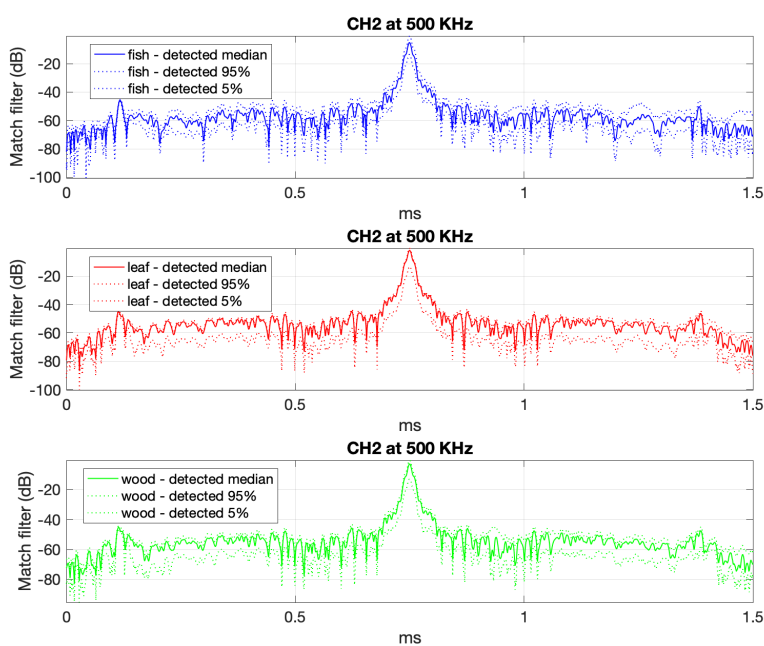

(b)

Fig. 5. Active ultrasound fish detection, $500 \mathrm{KHz}$ central frequency, $\mathrm{CH} 2$ : (a) spectrum and (b) conventional match filtering using the background reference function, only.

environment. It was shown that the obtained results present a high degree of accuracy with respect to the ground truth. Future studies include the inclusion of time adaptive estimation for continuous unsupervised monitoring.

\section{ACKNOWLEDGMENT}

This work has been developed in the framework of the ACOUEAU project, supported by the European Union Regional Development Fund. The authors would like to thank to Steeve Zozor, Amaury Nègre and Pascal Bellemain, form the GIPSA-lab, and to Géry Hachet, from the EDF R\&D and to Fabrice Huitorel from the OSEAN for their precious support in hardware and software development. 

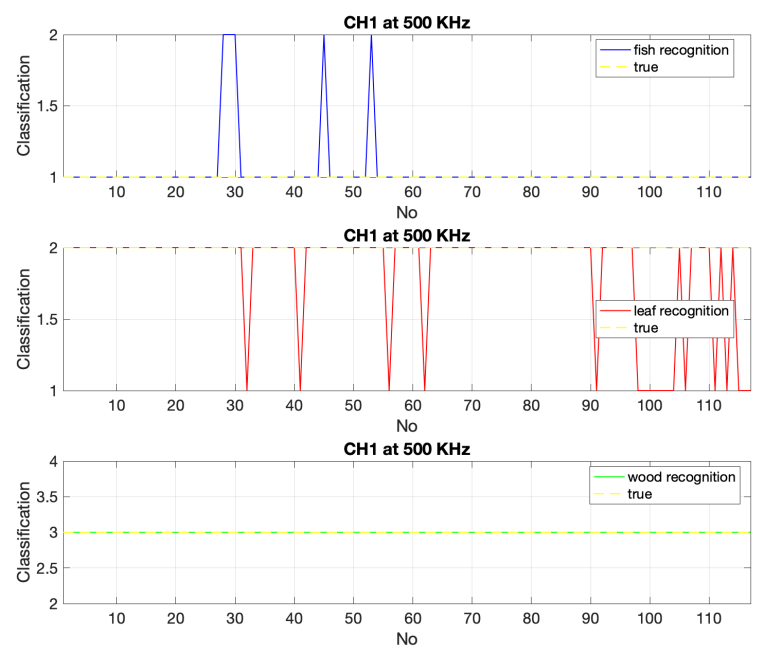

(a)
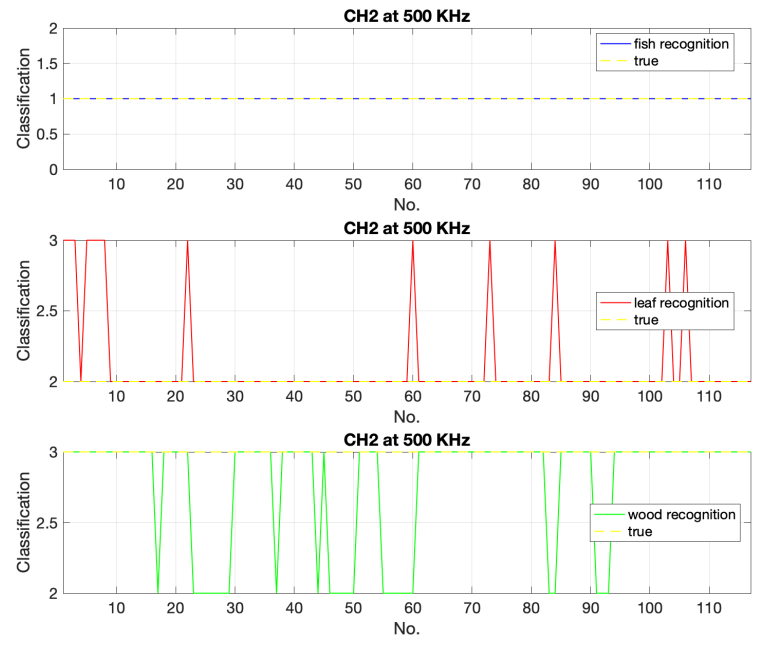

(b)

Fig. 6. Active ultrasound fish detection, $500 \mathrm{KHz}$ central frequency, classification results: (a) $\mathrm{CH} 1$ and (b) $\mathrm{CH} 2$.

\section{REFERENCES}

[1] ESHA European Small Hydropower Association, "Strategic study for development of small hydropower in the European Union," Tech. Rep. Renewable Energy House, 2008.

[2] M. Cuchet, M. Muhlbauer, C. Ratschan, A. Hartlieb, and B. Brinkmeier, "Behavioural experiments on the design of downstream fish passage facilities for potamodromous species," in Proceedings of the IAHR World Congress - Balance and Uncertainty, Brisbane, Australia, 2011, pp. 2792-2798.

[3] P.S. Pompeu and C.B. Martinez, "Efficiency and selectivity of a trap and truck fish passage system in Brazil," Neotropical Ichthyology, vol. 5, no. 2, pp. 169-176, 2007.

[4] M. Larnier, "Pool fishways, pre-barrages and natural bypass channels," Bulletin Français de la Pêche et de la Pisciculture, vol. 364, pp. 54-82, 2002.

[5] M. Larnier and F. Travade, "Downstream migration: problems and facilities," Bulletin Français de la Pêche et de la Pisciculture, vol. 364, pp. 181-207, 2002.

\begin{tabular}{|c|c|c|c|c|}
\hline & & \multicolumn{3}{|c|}{ Classification result } \\
\hline \multirow{4}{*}{ 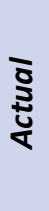 } & Class & Trout & Leaves & Wood \\
\hline & Trout & 96 & 4 & 0 \\
\hline & Leaves & 15 & 85 & 0 \\
\hline & Wood & 0 & 0 & 100 \\
\hline
\end{tabular}

(a)

\begin{tabular}{|c|c|c|c|c|}
\hline \multirow{4}{*}{ 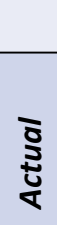 } & \multirow[b]{2}{*}{ Class } & \multicolumn{3}{|c|}{ Classification result } \\
\hline & & Trout & Leaves & Wood \\
\hline & Trout & 100 & 0 & 0 \\
\hline & Leaves & 0 & 89 & 11 \\
\hline & Wood & 0 & 22 & 78 \\
\hline
\end{tabular}

(b)

Fig. 7. Active ultrasound fish detection, $500 \mathrm{KHz}$ central frequency, confusion matrix: (a) $\mathrm{CH} 1$ and (b) $\mathrm{CH} 2$.

[6] G. Vasile, G. d'Urso, E. de Oliveira, J. Guillet, and E. Lungu, "Reference selection for an active ultrasound wild salmon monitoring system," in Proceedings of the MTS/IEEE North American OCEANS conference, Washington, DC, USA, 2015, pp. 1-4.

[7] G. Vasile, G. d'Urso, R. Charlatchka, and E. Lungu, "Calibration of an active ultrasound bedload monitoring system for underwater environments," in Proceedings of the MTS/IEEE North American OCEANS conference, Washington, DC, USA, 2015, pp. 1-4.

[8] G. Vasile, G. d'Urso, A. Goarant, E. de Oliveira, and E. Lungu, "Potential of active ultrasound monitoring systems for jellyfish detection," in Proceedings of the MTS/IEEE North American OCEANS conference, Monterey, CA, USA, 2016, pp. 1-4.

[9] G. Vasile, T. Petrut, G. d'Urso, and E. de Oliveira, "Iot acoustic antenna development for fish biomass long-term monitoring," in Proceedings of the MTS/IEEE North American OCEANS conference, Charleston, South Carolina, USA, 2018, pp. 1-4.

[10] G. Vasile, P. Bellemain, G. d'Urso, and E. de Oliveira, "Real-time wideband acoustic signal processing for fish counting," in Proceedings of the MTS/IEEE North American OCEANS conference, Charleston, South Carolina, USA, 2018, pp. 1-4.

[11] G. Vasile, E. Trouvè, M. Ciuc, P. Bolon, and V. Buzuloiu, "Intensitydriven-adaptive-neighborhood technique for POLSAR parameters estimation," in Proceedings of the IEEE Geoscience And Remote Sensing Symposium, Seoul, Korea, 2005, vol. 8, pp. 5509-5512.

[12] N. Besic, G. Vasile, J. Chanussot, S. Stankovic, J.P. Dedieu, G. d'Urso, D. Boldo, and J.P. Ovarlez, "Dry snow backscattering sensitivity on density change for swe estimation," in IEEE International Geoscience and Remote Sensing Symposium, Munchen, Germany, 2012, pp. 44184421.

[13] N. Besic, G. Vasile, J.P. Dedieu, J. Chanussot, and S. Stankovic, "Stochastic approach in wet snow detection using multitemporal SAR data)," IEEE Geoscience and Remote Sensing Letters, vol. 12, no. 2, pp. 244-248, 2015.

[14] G. Vasile, G. d'Urso, E. de Oliveira, and E. Lungu, "Online software nonlinearity correction for wideband active ultrasound monitoring systems," in Proceedings of the MTS/IEEE North American OCEANS conference, Anchorage, Alaska, USA, 2017, pp. 1-4.

[15] G. Vasile, G. d'Urso, E. de Oliveira, and E. Lungu, "Transmission waveform analysis for active ultrasound fish monitoring systems," in Proceedings of the MTS/IEEE North American OCEANS conference, Anchorage, Alaska, USA, 2017, pp. 1-4. 